\title{
Remediating Joyce's Techno-Poetics: Mark Amerika, Kenneth Goldsmith, Mark Z. Danielewski
}

\author{
David Vichnar \\ Charles University, Prague, Czech Republic
}

This paper attempts to evaluate the legacy of fames foyce's avant-gardism for the literary experimentation of Mark Amerika, Kenneth Goldsmith, and Mark Z. Danieleweski, three contemporary American writers and artists, working a hundred years after the first of Joyce's crucial four "shocks of the new" shook the foundations of fiction. In doing so, the paper attempts to bridge the divide between the historical avant-garde and the neo-avant-garde as defined by Renato Poggioli and Peter Bürger, and regarded disparagingly by critics like Robert Hughes. Positing a threefold legacy of Joyce's "revolution of the word" in its treatment of writing as trace, forgery, and idiom, the paper discusses Amerika's Grammatron, Goldsmith's uncreative writing, and Danielewski's House of Leaves as continuing in and expanding on the achievements of Ulysses and Finnegans Wake. This they achieve by pursuing what Marjorie Perloff has termed "differential poetics" and $\mathcal{N}$. Katherine Hayles has rethought as "Assemblage" - two poetic strategies dominant at the beginning of the $21^{\text {st }}$ century.

\section{Keywords}

Neo/avant-garde; $21^{\text {st }}$ century fiction; James Joyce; hypertext; uncreative writing; remediation

\section{Joyce's avant-garde in transition (1927-1938)}

When famous art critic Robert Hughes asked in the opening to his epochal The Shock of the New, "What has our culture lost in 1980 that the avant-garde had in 1890 ?" he was quick to draw a negative comparison and stressed as one of the things lacking in the culture of 1980 "the sense that art [...] could find the necessary metaphors by which a radically changing culture could be explained to its inhabitants" (Hughes 1). The question here will be not only 
what the literary experiment of the past two decades lacks that the Joycean avant-garde still had, but rather, more positively, what has it gained?

What Hughes describes as "loss of sense" reverberates through the debate surrounding the status, or indeed possibility, of the neo-avant-garde, an avant-garde outside of its original socio-historical context. To simplify, the question is whether avant-garde writing, reacting - in Renato Poggioli's influential wording - against "the flat, opaque, and prosaic nature of our public speech", and functioning as "at once cathartic and therapeutic in respect to the degeneration afflicting common language through conventional habits", whether this writing can just do with linguistic creativity as its aesthetic marker or whether its reaction must take place via a more direct critical engagement (Poggioli 37). Peter Bürger's Theory of the Avant-Garde construes modernism's non-instrumental aestheticism as signifying the artistic autonomy that makes modern art the institutional collaborator of modern bourgeois ideology:

To the extent that the means by which the avant-gardistes hoped to bring about the sublation of art have attained the status of works of art, the claim that the praxis of life is to be renewed can no longer be legitimately connected with their employment. To formulate more pointedly: the neo-avant-garde institutionalizes the avant-garde as art and thus negates genuinely avant-gardiste intentions. [...] Neo-avant-gardiste art is autonomous art in the full sense of the term, which means that it negates the avant-gardiste intention of returning art to the praxis of life. (Bürger $5^{8}$, emphasis original)

Bürger's political plotting of the art of modernity has direct repercussion for his detraction of post-war neo-avant-gardes. The shared intention on the part of the many historical avant-gardes of "returning art to the praxis of life", argues Bürger, falls flat when revived within a context where the avant-garde itself has become institutionalized as art, "the means of avant-gardism" no longer achieving "even the limited effectiveness" of the historical avant-gardes.

Transition magazine, during the eleven years of its activity (1927-38), published not only seventeen instalments from Joyce's "Work in Progress" to become Finnegans Wake in 1939, as well as all the twelve essays that were to form the Our Exagmination collection, but also many theoretical analyses, polemics, proclamations and defences of the work against its detractors. Its guiding spirits were Elliot Paul and especially Eugene Jolas, an American raised in Alsace, whose trilingualism was reflected in his own writings as well as in the cosmopolitanism of the journal, arguably the last of the great 
vanguard vehicles of high modernism, and definitely the only one (at least of such scale and durability) explicitly devoted to the avant-garde. In retrospect, Jolas characterized transition as "a workshop of the intercontinental spirit, a proving ground of the new literature, a laboratory for poetic experiment" (Jolas 1949, 13). Jolas's avant-garde undertaking was marked by certain belatedness: by the publication of its first number in 1927, the historical avant-garde had been on the wane if not defunct, and so transition gained another, retrogressive dimension: that of the archive. Jolas himself conceived of transition as a documentary organ dedicated to presenting what he referred to later as "pan-romanticism". A "Joycean avant-garde" based on Joyce's close alliance with transition magazine thus has the advantage of sidestepping the avant-garde/neo-avant-garde dichotomy (highlighted above by Bürger), this by virtue of its own belatedness and eclectic drafting of the many avant-garde "isms" as part of its programme.

Although present in transition from its very start, it was not until transition 11 (February 1928) that Joyce's work was drafted as part of Jolas's revolutionary programme. In "The Revolution of Language and James Joyce", Jolas presents the first sustained analysis of what needs to be accomplished for literature to be made genuinely "new":

The Real metaphysical problem today is the word. The epoch when the writer photographed the life about him with the mechanics of words redolent of the daguerreotype, is happily drawing to its close. The new artist of the word has recognized the autonomy of language and, aware of the twentieth century current towards universality, attempts to hammer out a verbal vision that destroys time and space. (Jolas 1929, 79, emphasis added).

In his famous manifesto, Jolas posits "the word" as "the Real metaphysical problem today" and argues for the necessity of substituting writing-asphotography with "a verbal vision" forged out of an "autonomous language". Jolas's reading of Joyce's "Work in Progress" emphasizes the materiality of the word as an agent of historical change while making a case for writing to exist intermedially: its "verbal vision that destroys time and space" explicitly positioned at the intersection of photography, phonography, radio, film and television.

Finnegans Wake explores the materiality of language at the level of the signifier via the pun and the portmanteau, foregrounding the indivisibility of meaning from its material representation. Joyce's "whorld" ( $F W$ 100.29) order 
has the merit of being based on language - which is man-made - rather than on incomprehensible cosmic events. Joyce thus simultaneously desacralizes both religion and language by means of signifiers that no longer stand for something signified but are objects in their own right, the Beckettian "something itself", the subjects of multiple intentions inviting different interpretations. Their complexity makes meaning not something already accomplished, waiting to be expressed, but instead functioning as a perspective of semiotic production. Joyce's use of the portmanteau word and multilingual punning in creating the Wakean language can be seen as variously destabilizing identity - of language, history, nation, and last but not least, of its own existence as text, within the potentially infinite re-writings imposed upon it in the reading process. In one of the many self-referential passages, the Wake describes itself as a "scherzarade of one's thousand one nightinesses" in which "that sword of certainty which would indentifide the body never falls" ( $F W 5^{1.4}{ }^{-6}$, emphasis added). To indentifide is to identify with an "indentation" - for fiction functions and operates as a product of writing through the operation of reading. Furthermore, the very same sentence indents indentifide as idendifine, performing one instance of the sundry internal variations and differentiations that run the whole gamut of the Wakean "indentity of undiscernibles" ( $F W$ 49.36-50.1) where the only (s)word that never falls is that of certain and unambiguous identity. The reader's identity, too, undergoes destabilization in that every reading of the Wake becomes split between the eye that registers multiplicity and the voice which can sound only one text at a time. In other words, every one of the potentially inexhaustible readerly realizations indents the identity of the written: with the Wake more so than with any other text, to read is to re-write, to counter-sign. Every reading is a performance with a difference of the textual material. Indenting stretches out into legal discourse not only via the contractual relation of indenture, but also in that it denotes forging, duplicating - and the voice's duplication, the performance of the written, is nowhere more forcefully limiting than in the Wake.

Jolas was among the first readers of Joyce to emphasize this intermediality of his writing. Much later, Donald Theall coined for this quality of writing the term "technopoetics", by which he meant Joyce's poetic practice as a mode of re-situating the medium of the book within the new communicative environment within which "the very nature of the word, the image, and the icon also changes", and consequently both writing and speech "are subsumed into entirely new relationships with other sensory input and media" (Theall 24). Finnegans Wake, within the avant-garde context of the new technologies it 
thematizes, becomes more than "a polysemic, encyclopedic book designed to be read with the simultaneous involvement of ear and eye" - its additional role is to act as "a self-reflexive book about the role of the book in the electromachinic world of the new technology" (Theall 20). This happens most explicitly in the Wake but to a lesser degree also throughout Joyce's oeuvre, this by Joyce's sustained exploration of the materiality of language, which occurs chiefly on three levels:

1) writing as a concretization of the sign, the conception of words as traces disseminated in the materiality of the book; the typographical foregrounding of letters, signs and words as distinct objects;

2) writing as plagiarism, the forgery of fiction, the word as always belonging to an other and in need of appropriation; writing as parodic subversion of established discourses and styles;

3) and writing as destabilization of the signifier as vehicle of established univocal meaning by means of multilingual punning and the technique of the portmanteau, a treatment of words as composite objects.

In a word, Joyce's "technopoetics" conceives of writing as trace/link, plagiarism/ repetition, and idiom/objectification. This has also implications for Joyce's construction of the narrative: from the skeletal frameworks of the series of mythic Homeric correspondences behind Ulysses, and the overarching looped dream-narrative of Finnegans Wake, to further refined ordering mechanisms, narrative symmetries and asymmetries, permutational configurations, acrostic structures, fractal patterns, and so on, Joyce's poetics is structural and mechanistic. Joyce's work with frameworks and structures also implies two principal operations: conceiving of the centre as either absent or unreachable or ever-shifting and multiple, and "emptying" his own creative impulses in a "playgiarist" recreation from the textual materials of the traditions at his disposal. What, then, is the legacy of Joyce's materiality of language and his re-thinking of the book medium for the "experimental" writing of the last twenty years? Three prominent, even "cult", experimentalists exemplify these chief three tendencies of Joyce's writing.

\section{The Materiality of the Electrosphere in Mark Amerika's GRAMMATRON (1997)}

The basic theoretical implications of Joyce's poetics have, in turn, solicited their 
re-appropriation in the artistic praxis of our digital present and its culture of sampling and remixing. Joyce's seminal importance for the theorization and practice of artistic hypertext and hypermedia has been well-documented. Here, it will suffice to rehash it just by way of sketching out parallel genealogies: the theoretical one, beginning with Ted Nelson and Marshall McLuhan in the mid-6os and culminating with Jay D. Bolter, Stuart Moulthrop, and George P. Landow in the mid-gos, with Donald Theall, Darren Tofts and Louis Armand acting as "transmitters" of hypertext theory into Joyce studies; and the practical/artistic one, starting with Jorge Luis Borges's textual labyrinths, Raymond Queneau's Hundred Thousand Billion Poems and Nabokov's Pale Fire, and via the surficition of Raymond Federman and Ronald Sukenick, as well as the punk aesthetics of William Burroughs and Kathy Acker, reaching the numerous writers and artists working with/in the medium post-2000. The example here of how systematic and "playgiarist" impulses of Joyce's poetics served as inspiration for some pioneering conceptual cyber-work in the digital hypertextual age is Mark Amerika's 1997 GRAMMATRON.

Mark Amerika's GRAMMATRON has been described by The New York Times as "a colossal hypertext hydrogen bomb dropped on the literary landscape [...], grappling with the idea of spirituality in the electronic age" (Qtd. Amerika online). Amerika's net art project, launched in 1997 and garnering over 500,000 visitors upon its release, became in 2000 the first online artwork ever to be exhibited at the Whitney Biennial of American Art. Its motto, "I link therefore I am", is as much the creed of any hypertextualist as a formula known to all Joyce readers. It is the Wake's almost cabbalistic obsession with textual recombination and inter-linkage, with the deciphering of codes \& pluralizing of readings, that Mark Amerika chooses to revisit in his own recreation of the Golem myth for the digital age. Just as the Wake, GRAMMATRON is a paradoxical, looping narrative that chooses confusion over coherence, and in which individuals manifest inside the electrosphere as both fleshy and digital versions of themselves simultaneously, their existence "written" by the machine as they experience it.

A self-described "addict of Degenerative Prose $[\ldots]$ that re-synthesizes hybridized forms of prose including fiction, faction, friction and non-diction", Amerika created GRAMMATRON out of eleven hundred (partly randomized) text elements and 2000 links (Amerika \& Sukenick 1). To this he added $40+$ minutes of original soundtrack delivered via Real Audio 3.o, hyperlink structures as specially-coded Javascripts, a virtual gallery featuring scores of animated and still-life images, and more "storyworld development" than 
any other narrative created exclusively for the Web ever before. The work consists of different text-layers from which the user is free to choose, including a theoretical essay titled "Hypertextual Consciousness", the animated text "Interfacing", and the main hypertext "Abe Golam". Narrated from various authorial perspectives, the story keeps searching for its protagonist Abe Golam, a pioneering Net artist who creates GRAMMATRON, a writing machine. Endowed not with the Word (as in the original myth of the Golem), but with forbidden data - a specially coded Nanoscript - the creature becomes a digital being that "contains all of the combinatory potential of all the writings" (Amerika online). Clicking on the hyperlinks in a similar fashion to how today, 20 years later, one would in Wikipedia, the reader follows Abe Golam's search for his "second half", a programmer named Cynthia Kitchen, whose playful codes of interactivity lead both Golam and readers through a multi-linear text-scape with eerie-sounding remixes of rock n' roll tunes and some of the grainiest gifs on the Internet of 2019.

What is GRAMMATRON? According to Amerika, "many things at once", but the things he does specify include "experimental narrative riffs from the likes of James Joyce, Arno Schmidt, and Jean-Luc Godard" (Amerika 2007, 167-8). Indeed, GRAMMATRON is most explicitly indebted to Derrida's "grammatology" as the study of signification within systems of inscription, to which it alludes not only by its title, as well as to Wittgenstein's koan that "the self is grammatical". But as a story of a Golem/writing machine in the age of electronic textuality, it is also steeped in the ritualism of naming, the practice of encoding and decoding the sacred name, and the self-emptying and replenishment involved in any re-creative, plagiarist activity - practices and motifs remixed from Joyce's oeuvre. Or, rather "playgiarist". In his book of essays titled META/DATA: Digital Poetics, Amerika refers to his practice of remixing as "playgiarism", associating it with "an entire heritage or rival tradition of literature" (which apart from Joyce includes Burroughs, Federman, and Acker), whose authors readily write cyberspace as a kind of playgiaristic practice, its supplemental " $y$ " signifying performance in the "self-organizing world of the artificial intelligentsia" (Amerika 2007, 43-4).

As opposed to plagiarism, playgiarism foregrounds ludic irreverence toward source text(s) and their kaleidoscopic or "collideorscapic" (FW 143.28) reshuffling and recombination. In another instance of opposites meeting, Joyce's altered ego Shem associates his plagiarism not with play but with heresy: his "piously forged palimpsests" falling off his "pelagiarist pen" ( $F W$ 182.2-3). Who does this pen write, and cursor remix, for? "His producers 


\section{DAVID VICHNAR}

are they not his consumers?" ( $F W 497 \cdot 1)$, asks the Wake of itself rhetorically, knowing full well it will only ensure its immortality by producing ever-new consumptions of itself, keeping writers \& artists busy remixing it for centuries to come. In his recent work Remixthebook, Amerika posits that the general idea behind his version of applied aesthetics/remix(grammat)ology is "don't do as I say or do as I do but remix your own creative potential as a singular fringe-flow sensation" since (and this is a Wakean lesson), "the One is not one" (Amerika 2011, 53).

It is not only by performing the narrative coincidence of, and forging a textual link between, binary archetypes, or obsessing over the technology of writing and impermanence and mutability of all products of inscription, that GRAMMATRON is informed by Finnegans Wake. The affinity also pertains to their shared metafictional play with the authority of authorship as the absent centre: just as the Wake everywhere foregrounds its status of "a letter selfpenned to one's other" (FW 489.32), GRAMMATRON is the personification of the Golem, which is also a personification of Amerika the artist. It is chiefly through the literalization of the Wake's "abnihilisation of the etym" ( $F W$ 353.22) as the writing blinks on and off the screen, the McLuhanesque hyper-medium being the "hyper-massage", that GRAMMATRON recreates the seemingly infinite, recombinant (text-)space of the Wake's paronomasia in the materiality of its electrosphere.

In so doing, Amerika not only asserts his own avant-garde credentials, but also revisits and upgrades Eugene Jolas's co-option of Joyce's project under an avant-garde rubric on the pages of transition. There is something futurist and dystopian about Amerika's GRAMMATRON, a project whose monstrosity and naiveté could have only been born in the early chaotic days of 199 os cyberculture, when the Internet's utility still lurked in-between its gears. GRAMMATRON is the raw expression of early Internet adoption, and an allegory for the tug-of-war between the artists that flocked to create in cyberspace, and the corporate entities that sought to turn it into a corpocracy. Amerika depicts the digital world as a living, breathing warzone - a land too vast to be tamed. Similar to the Wake's polysemic self-reflexive meditation on its own status of the book at the dawn of the electro-machinic world of new media technologies, Amerika's 1997 project marks a historical moment in which the digital world online was a dangerous place to get lost in, not yet partitioned by corporations and auctioned off to the highest bidder.

By existing as moving images on the alternately full/empty screen of fleeting textual formations, the slides of GRAMMATRON attempt a rethinking 
of representation: "moving beyond the knowing and entering a world of immersive topographies that open up unknown narrative worlds composed of unstable identities, ambiguously located intentions, and surrogate lovers" (Amerika online). Just as the Wake, GRAMMATRON brims with abstract thought, self-reflexion, self-redefinitions, and descriptions of the indescribable. It pulsates with an acute fear of the Internet and an urgent desire to harness it. GRAMMATRON's, just as the Wake's, is "a language that persists despite itself", querying of the reader, much as the Wake does, "Can you rede its world?" (FW 18.18).

\section{Kenneth Goldsmith's Uncreative Writing in Fidget (1997) and Head Citations (2002)}

Intriguingly, even though tacitly, the opening premise of Kenneth Goldsmith's own recent manifesto, Uncreative Writing: Managing Language in the Digital Age (2011), echoes both Jolas's and Theall's intermedial parallels to the effect that writing, in the digital age of the web, has "met its photography", its technological extension that can transpose it into a whole new medium and simultaneously bring about a major change in its functioning. If painting, a hundred years ago, reacted to photography by abstraction, then, Goldsmith observes, the reaction of writing could be the opposite: "It appears that writing's response - taking its cues more from photography than painting could be mimetic and replicative" (Goldsmith 2011, 15).

This "mimetic and replicative" writing is then contextualized as part of the development of literary modernity: from Stéphane Mallarmé via Gertrude Stein and Ezra Pound to the language-poetry of Charles Bernstein. An important step in this process was again taken by Joyce's Wake and its original encrypting, through writing, of the medium of the voice. Even though, on page, Finnegans Wake, remains for Goldsmith "a book of compound words and neologisms, all of which look to the uninitiated like reams of nonsensical code", rendering it, "on first sight [...], one of the most disorienting books ever written in English", when read aloud and heard, its functioning undergoes a marked change:

But hearing Joyce read/decode a portion of Finnegans Wake, most famously his own recording of the "ALP" section, is a revelation: it all makes sense, coming close to standard English, yet on the page it remains "code". 
Reading aloud is an act of decoding. Taken one step further, the act of reading itself is an act of decoding, deciphering, and decryption. (Goldsmith 2011, 19)

The virtual omnipresence, in contemporary culture, of text and writing as code, calls for a consideration of what Goldsmith dubs textual ecology, "an ecosystem that can encompass language in its myriad forms". His literary analogue, again, is Joyce and his meditation on the universal properties of water in the "Ithaca" episode, the musings of Bloom "the waterlover, drawer of water, watercarrier" ( $\left.U_{17.183}\right)$, inspiring Goldsmith's rumination on digital language:

When Joyce writes about the different forms that water can take it reminds me of different forms that digital language can take. Speaking of the way water puddles and collects in "its variety of forms in loughs and bays and gulfs", I am reminded of the process whereby data rains down from the network in small pieces when I use a Bit-Torrent client, pooling in my download folder. When my download is complete, the data finds its "solidity in glaciers, icebergs, icefloes" as a movie or music file. When Joyce speaks of water's mutability from its liquid state into "vapour, mist, cloud, rain, sleet, snow, hail", I am reminded of what happens when I join a network of torrents and I begin "seeding" and uploading to the data cloud, the file simultaneously constructing and deconstructing itself at the same time. (Goldsmith 2011, 27)

Over the past fifteen years, Goldsmith has been one of the most prolific and influential practitioners of conceptual writing, and one also to position himself most explicitly within the genealogy of Joyce's poetics. To pick just two examples: Goldsmith's 2000 text Fidget opens as follows:

Eyelids open. Tongue runs across upper lip moving from left side of mouth to right following arc of lip. Swallow. Jaws clench. Grind. Stretch. Swallow. Head lifts. Bent right arm brushes pillow into back of head. Arm straightens. Counterclockwise twist thrusts elbow toward ceiling. Tongue leaves interior of mouth passing through teeth. Tongue slides back into mouth. Palm corkscrews. Thumb stretches. (Goldsmith 2000, 1)

In a letter to critic Marjorie Perloff, Goldsmith explains that, divided up into 
11 sections, corresponding to the eleven hours he was awake on June 16, 1997, Fidget is meant as homage to the hour-by-hour chapters of Joyce's Ulysses, the epic of the human body. And as in Ulysses, different actions dominate different hours. Telling the "truth", as Goldsmith quickly discovers, may be the biggest "fiction" of all, it being "humanly impossible to track all of one's bodily movements" (Goldsmith 2000, 91). And despite the "no editorializing" imperative, Goldsmith's text is a highly stylized one - by means of the elision of all articles or "unnecessary" words throughout, but especially in the last chapter, where a drunk sequence is conveyed through a rerun of the first chapter in reverse, bringing the whole text to a close (SLIDE). Goldsmith's transcription of the first chapter in reverse order achieves some poetic effects, words achieving new unexpected meanings: a key word is "morf" (from), a word highly applicable in the context along with "woble" (elbow), or "pil" (lip); and, as is usually the case whenever the body is concerned, there is much "dna" (and) about.

Fidget's breakdown of bodily functions into their smallest components has a strong effect of defamiliarization, a synecdochic decentring of human subjectivity, which also marks so many of the descriptions in Ulysses of bodily movements or actions. One of the most prominent examples is the "lipspeech" motif in "The Sirens" episode:

"Miss Douce's wet lips said." (U 11.72)

"Her wet lips tittered." (U11.76)

"Lenehan's lips over the counter lisped." (U 11.328)

"Miss Douce's lips that all but hummed [...] the oceansong her lips had trilled." (U 11.377)

"Richie cocked his lips apout." ( $U$ 11.727)

"his lips that cooed a moonlight nightcall." (U11.1088)

Here's a list of six different pairs of "lips" and their activities - saying, tittering, lisping, humming, trilling, pouting, cooing - all usually associated with the domain of the whole of the body, usually presented pronominally ("she said", "he lisped", etc.) as a grammatical subject implying an undivided, efficient self of which the organ is mere appendage. Joyce's conscientious reversal of this relation aims to liberate the body from a dictatorial, globalizing will and allow its organs their own energies. Thus, although engaging in the same activity of defamiliarizing the body by fictional means, Goldsmith's and Joyce's poetics produce vastly different results: whereas for Goldsmith, 
the body exists mechanically, repetitively, and his verbal deformations are a mere reversal of the stability of the norm, Joycean syntactic deformations bring about a destabilization of the norm itself.

In 2002, Goldsmith created a different "uncreative project". In Head Citations, he presents 800 variations - paronomasiac and malapropistic - on famous pop song lyrics. Craig Dworkin's back cover blurb for the book even quotes Finnegans Wake: “'Our cubehouse still rocks as earwitness' to this book of earrors and close listing, as Joyce would put it. So prick up your arse and glisten well. Besides, 'e'erawhere in this whorl would ye hear sich a din again?" To be sure, the parody of the mythology of the popular song is performed with a similar ear for possible eroticized détournement, and to similarly amusing effect, as in the Wake. Head Citations (the title coming from "11. She's giving me head citations" [Goldsmith 2002, 7]) moves from "1. This is the dawning of the age of malaria. 2. Another one fights the dust. 3. Eyeing little girls with padded pants. 4. Teenage spacemen we're all teenage spacemen" (Goldsmith 2002: 7) all the way to "8oo. Sleep in heavenly peas" (Goldsmith 2002, 87), and throughout, its punning humour brings about some destabilizing effects, as for instance in this passage:

673. Are you going to Harvard or Yale.

673.1. Are you going to Scarlet O'Hare.

673.2. Parsley, sage, rosemary and Todd.

673.3. Parsley's age grows merry in time.

673.4. Parsley's angels, Mary and Tom.

673.5. Partly saved, Rosemary and Tom.

673.6. People say it was Mary and Tom.

673.7. Parsnips say Rosemary is blind.

(Goldsmith 2002, 72)

Yet, to equate or parallel Goldsmith's text with Finnegans Wake solely on the basis of their parodic plagiarism of the clichés of popular culture is again inadequate without stressing the different effects to which this strategy is deployed. To take another similarly enumerative example from Finnegans Wake, Joyce's reworking of the "boys will be boys" saying:

"till byes will be byes" ( $F W 11.8)$

"Brights we'll be brights" ( $F W$ 245.4-5) 
"Childs will be wilds" ( $F W$ 246.21-2)

"plubs will be plebs" (FW 312.33)

"biestings be biestings" (FW 406.34)

Again, a series of variations, formally similar to Goldsmith's "Scarborough Fair" lyrics. In the first transformation, the proverb also alludes to the expression "let bygones be bygones", in a passage in which paradoxically, remains of the past are gathered up, with bygones not let to be bygones, and the past serving the future. The variations, "Brights we'll be brights" and "Childs will be wilds" are said in connection with children at play who have been called home for dinner. The fourth example is found in $F W$ II.3, in the famous pub scene, hence "plubs will be plebs", identifying the pub as a meeting place for the plebs, the lower working classes. Finally, in a description of Shaun's eating habits in III.1, the phrase "biestings be biestings", plays on the Anglo-Irish word denoting, according to McHugh, "milk from a cow that has just calved" (McHugh 406), while alluding to the English word "beast", and especially to its German equivalent "Biest".

So, although less homonymous and homophonous than Goldsmith's and driven more by syntax and alliteration than sound, Joyce's variations endow the ancient clichés with a variety of new meanings garnered from contexts ranging from the historical to the socio-pedagogical to the political, a contextual depth that Goldsmith's mechanical, context-less permutations almost purposefully avoid.

\section{Mark Danielewski's Typographical Fireworks in House of Leaves (2000)}

A counterpart to Mark Amerika's hypertextual exploration and Kenneth Goldsmith's verbally conceptual experimentation is Mark Danielewski's momentous 700-page novel House of Leaves (2000). The most concise description of the book's narrative structure would be a story about a story about a story about a film about a house with a black hole in it, further reworked by an unspecified editorial body, which already reveals it as one of multiple removes and framings. The novel's plot is comprised of an extensive narration of a film by a blind man, Zampano, who dictates his critical commentary about the documentary film The Navidson Record shot by photographer Will Navidson. 
The film details Navidson and his family's terrifying ordeal living in a house whose insides gradually grow larger than its frame; the house's hallway mutates into a labyrinthine black hole that devours sound, light, and eventually human beings. After Zampano's mysterious death, his scholarly manuscript is discovered by one Johnny Truant, a psychologically damaged but highly literary maverick who edits and pieces together Zampano's fragmentary legacy, interweaving it with his own narrative layer through a set of footnotes. Truant's version of Zampano's Navidson Record is then edited by the corporate entity, "The Editors", whose presence is indicated by the monosyllabic "Ed". Proceeding in an objective tone that contrasts with Truant's emotive commentary, the Ed. produce an additional set of editorial commentary, footnotes demarcating emendations to the text or acknowledging missing information.

Of equal importance is the book's graphic outlook and textual presentation. Each of these narrative voices is identified by a different font and is associated with a specific medium: Zampano's academic commentary appears in Times Roman, the font associated with newspapers and the linotype; Truant's footnotes are in Courier, imitating a typewriter's inscription, and thematically identifying him as the middleman, the "courier" of the manuscript; the terse notations from the Ed. are appropriately presented in the Bookman font. Danielewski's expressive form, on the typographical level, develops in the course of the novel as, together with the progressive collapse of the inner spatial coordinates of the House, comes also the collapse of the standard typographical page, its linearity and uniformity giving way to a vertiginous experience of the typographical carnivalesque. Danielewski's textual and typographical exploration of the book as material object and its position within the electronic media is again an undertaking essentially Joycean, though - just as Amerika's and Goldsmith's - Joycean with a difference.

House of Leaves is, in more than one sense, a monstrosity - primarily, as a print novel for the digital age, a printed text that exists hypertextually on the page. While indulging in the typographical carnivalesque, at the same time, Danielewski's text is structured explicitly as hypertext, both on the micro-level of the text, as well as on the macro-level of the concept. Every appearance of the word "house" is blue, the colour of an active hyperlink on the Internet. Besides imitating the interface and navigation structure of the Web, House of Leaves positions itself as a node on the information network before its narrative even begins. Beneath the copyright and publisher's information is the web address for the official House of Leaves website: www.houseofleaves. 
com. Sharing the title of the novel and its publication date, the website is the novel's double that turns its production into an ongoing process featuring a Bulletin Board, a virtual space where readers form a community based on real-time communication about the novel, and as of March 2019, it boasts a fellowship of over 94,000 registered members and a trove of over 250,000 articles.

Thus, rather than viewing the central symbol of the text, the eponymous House, as an updated gothic/horror version of a (Borgesian) textual labyrinth, there is evidence enough to suggest that more appropriate is to treat Danielewski's House of Leaves as fictional conceptualization of the situation of the book in a digital age. In his introduction, Johnny Truant warns the reader that "old shelters - television, magazines, movies - won't protect you anymore. You might try scribbling in a journal, on a napkin, maybe even in the margins of this book. That's when you'll discover you no longer trust the very walls you always took for granted" (Danielewski xxiii). It is not just the man-eating house that haunts House of Leaves; it is the mutation of "old shelters" (i.e., books), induced by digital technology. Zampano identifies the digital as the ghost haunting the film The Navidson Record: "even though the spectre of digital manipulation has been raised in The Navidson Record, to this day no adequate explanation has managed to resolve the curious enigma" (Danielewski 2000, 335).

Danielewski's own pronouncements on the subject of the novel display his broad understanding of textuality that becomes enhanced, rather than displaced or obsolesced, by the digital. Thus, if "the analogue powers of these wonderful bundles of paper" might "have been forgotten" in the internet age, "I'd like to see the book reintroduced for all it really is" (Danielewski: online). What the book "really is", at the turn of the millennium, is print inserted into a contemporary context and "reintroduced" to a specific readership, one that is digitally literate. That House of Leaves presents a fictional conceptualization of the situation of the book in a digital age is brought home by the novel's "envoy". On the last page of the book, after all the appendices and extensive Index, there is the final textual hyperlink that ends by opening outwards and connecting its print body to the Internet. Following the publisher's credits and copyright information, the last page of the book contains the following "imagetext": 
DAVID VICHNAR

Fig. 1 Danielewski: 709

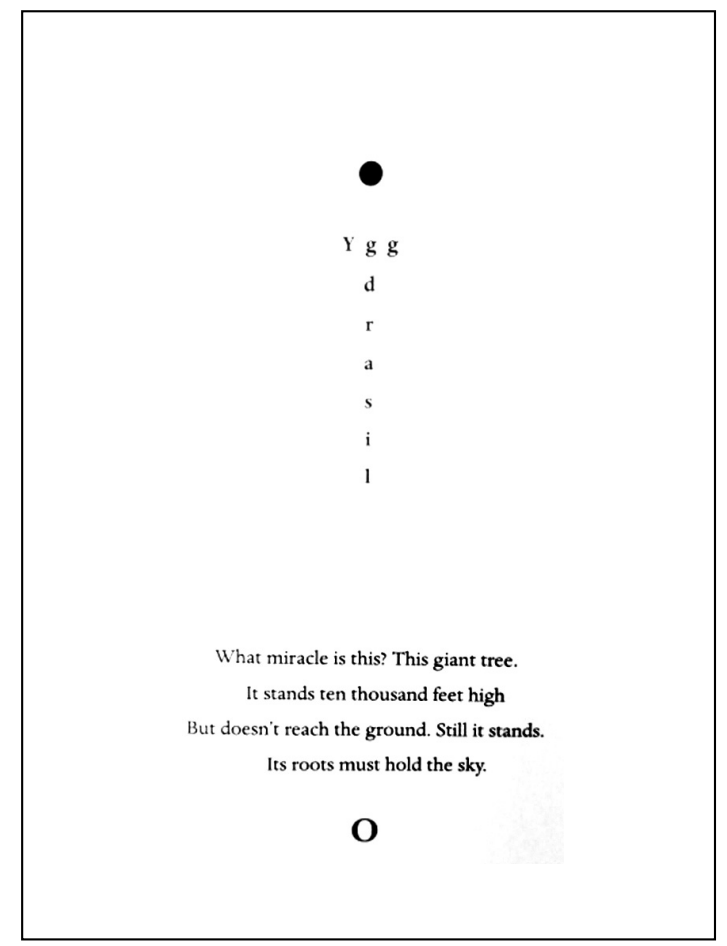

In Scandinavian mythology, Yggdrasil, the tree whose branches hold together the worlds of the universe, is believed to be ash - the last of the innumerable self-reflective moments, referring to the hyper-walls of the house on Ash Tree Lane. In a final punning moment, this allusion is not only mythological and metaphoric but real-life and material: for Yggdrasil was the name of an early, mid-gos, version of the Linux Operating System. This subtle reference thus links a cultural myth explaining the universe as network to a computer operating system structuring the Internet culture, a reference that is further enhanced by the presentation of a large, bold "O" beneath the stanza describing the Yggdrasil tree as an invisible network. As critic Jessica Pressman has argued convincingly, "the open O corresponds to the dark dot at the top of the page and represents opposing states - absence/presence, zeros/ones - the bits of patterned information that construct the digital world" (Pressman 120). 
To cast Danielewski in the role of Joyce's follower is again tempting but challenging. Despite evident parallels and similarities in their experimentation with typography and "paperspace", the typographical fireworks of House of Leaves exist iconically, as visual representations of an experience of a different medium:

The whole place keeps shuddering and shaking, walls cracking only to melt back together again, floors fragmenting and buckling, the ceiling suddenly rent by invisible claws, causing moldings to splinter, water pipes to rupture, electrical wires to spit and short out. Worse, the black ash of below, spreads like printer's ink over everything, transforming each corner, closet, and corridor into that awful dark. (Danielewski 345)

In the pivotal scene where Will Navidson's brother, Tom, is swallowed by the House into its dark abyss - a moment of horror and ontological impossibility the "black ash" of the house's internal abyss is compared to "printer's ink". And throughout House of Leaves, the words and letters exist as that: as icons of their own materiality, pictures of a non-linguistic reality, a conception departing from, if at odds with, Joyce's multiple layering of meaning in the linguistic density of his late avant-garde work.

\section{Conclusion: Remediating Assemblages}

Amerika's attempt at rethinking of literary representation within electrosphere, Goldsmith's conceptual experimentation with linguistic innovation, Danielewski's textual and typographical exploration of the book-object - all attest to the fact that Joyce's heritage for the contemporary literary experiment springs chiefly from his avant-garde techno-poetics and intermedial writing in Ulysses and Finnegans Wake.

What marks Grammatron, Fidget and House of Leaves as Joyce-inspired, and yet original developments in poetics at the turn of the twenty-first century is their existence in multiple media realizations, the textual only one of them, so that intermediality (understood as the blend of word and image or word set to music or recited on film) is no longer quite applicable to these works. Grammatron's two thousand links, 40+ minutes of Real-Audio original soundtrack, innumerable hyperlink structures as specially-coded Javascripts, its virtual gallery featuring scores of still-life images, all this creates out of the 
materiality of its electrosphere a seemingly infinite, recombinant (text-)space in which to lose oneself. Fidget exists as a musical version, a gallery installation at Whitney, and the Java applet e-version, and so Marjorie Perloff rightly identifies it as an instance of differential poetics, the production of a work that exists differentially in alternate media, "as if to say that knowledge is now available through different channels and by different means" (Perloff 101). House of Leaves' radical opening of text to hypertext, its existence in both print and digital media, its processual state of a never-ending becoming, all these mark it as an example of what Katherine Hayles has termed an "Assemblage" and defined as "a cluster of related texts that quote, comment upon, amplify, and remediate one another" (Hayles 278).

To be sure, there is still the historical vs. neo-avantgarde divide that prevents the all-too-ready label "Joycean" from being easily applicable to Amerika's, Goldsmith's, or Danielewski's creative reworkings of avant-garde poetics. To come back to Hughes, what was deployed by Joyce in order to critique his lived experience and to provide "the necessary metaphors by which a radically changing culture could be explained to its inhabitants", becomes neutralized as an exercise in "playgiarism" in Amerika's remixology, eschewed in Goldsmith's programmatic lack of critical engagement, and abandoned for the sake of fetishizing typography in Danielewski. Still, Amerika's, Goldsmith's and Danielewski's "re-mediations" of fiction designed to involve "all modes of sensory input" practice and directly engage in what the project of Joyce's "techno-poetics" theorized and anticipated some sixty years prior: the changing role of literacy and the book medium in the electro-machinic world of the new digital technology.

\section{Works Cited}

Amerika, Mark. Grammatron. January 1997. Web. Accessed 15 March 2019. http://www.grammatron.com/about.html

Amerika, Mark and Ron Sukenick (eds). Degenerative Prose. Champaign: FC2 Press, Illinois University Press, 1995. Print.

---. Meta/Data - A Digital Poetics. Cambridge, Mass: MIT Press, 2007. Print.

---. Remixthebook. Minneapolis: University of Minnesota Press, 2011. Print.

Bürger, Peter. Theory of the Avant-Garde. Trans. Michael Shaw. Minneapolis: University of Minnesota Press, 1984. Print.

Danielewski, Mark Z. House of Leaves. New York: Pantheon Books, 2000. Print. 
Danielewski, Mark Z, and Sophie Cottrell (eds). "Bold Type: Conversation with Mark Danielewski," April 2002. Web. Accessed 15 March 2019. www. randomhouse.com/boldtype/o40o/danielewski/interview.html

Goldsmith, Kenneth. Fidget. New York: Coach House Books, 200o. Print.

--. Head Citations. Great Barrington: The Figures, 2002. Print.

---. Uncreative Writing: Managing Language in the Digital Age. New York: Columbia University Press, 2011. Print.

Hayles, N. Katherine. "Translating Media: Why We Should Rethink Textuality." The Yale Journal of Criticism, vol. 16, no. 2. 2003: 263-29o. Print.

Hughes, Robert. The Shock of the New. New York: Alfred Knopf, 1991. Print. Jolas, Eugene. "The Revolution of Language and James Joyce." Our Exagmination Round His Factification for Incamination of Work in Progress: A Symposium. Ed. Samuel Beckett. New York: New Directions, 1929. 77-93. Print. ---. (ed). Transition Workshop. New York: The Vanguard Press, 1949. Print.

Joyce, James. Finnegans Wake. London: Faber and Faber, 1939. Print.

---. Ulysses. New York: Random House, 1922 (1986). Print.

McHugh, Roland. Annotations to Finnegans Wake ( $4^{\text {th }}$ edition). Baltimore: Johns Hopkins University Press, 2016. Print.

Perloff, Marjorie. "Vocable Scriptsigns': Differential Poetics in Kenneth Goldsmith's Fidget." Kenneth Goldsmith. Fidget. New York: Coach House Books, 2000. 90-102. Print.

Poggioli, Renato. The Theory of the Avant-Garde. Cambridge, Mass: Harvard University Press, 1968. Print.

Pressman, Jessica. "House of Leaves: Reading the Networked Novel." Studies in American Fiction, vol. 34, no. 1, 2006: 107-28. Print.

Theall, Donald. "Beyond the Orality/Literacy Dichotomy: James Joyce \& the Pre-History of Cyberspace." Eds. David Vichnar and Louis Armand. Hypermedia Foyce. Prague: Litteraria Pragensia Books, 2010. 17-35. Print.

\section{Acknowledgement}

This work was supported by the European Regional Development FundProject "Creativity and Adaptability as Conditions of the Success of Europe in an Interrelated World" (No. CZ.02.1.01/o.o/o.o/16_019/oooo734).

Older versions of some parts of this paper have appeared in David Vichnar, Subtexts: Essays on Fiction (Prague, 2015) and in Parallaxing Foyce: Festschrift for Fritz Senn, eds. Penny Paparunas \& Frances Ilmberger (Tübingen, 2016). 
DAVID VICHNAR is Senior Lecturer at the Department of Anglophone Literatures and Cultures at Charles University Prague. In 2014, he received a double PhD (from Charles University and Université de la Sorbonne Nouvelle, Paris) for his thesis mapping James Joyce's legacy for the post-war Anglo-American and French literary avant-gardes. His publications include Foyce Against Theory (2010) and Subtexts: Essays on Fiction (2015), his edited publications include Hypermedia Foyce (2010), Thresholds (2011), Praharfeast: James foyce in Prague (2012) and Terrain: Essays on the New Poetics (2014). He works as an editor, publisher and translator. He co-edited VLAK magazine (2010-15); since 2009, he has acted as programme director of the annual Prague Microfestival and manages Litteraria Pragensia Books and Equus Press. He also acted as chief editor of Hypermedia foyce Studies, the first online journal of Joyce scholarship. His articles on contemporary experimental writers as well as translations of contemporary poetry (Czech, German, French and Anglophone) have appeared in numerous journals and magazines.

david.vichnar@ff.cuni.cz 